Atrkivoc

Free to Authors and Readers
A Platinum Open Access Journal

for Organic Chemistry
Paper

DOAJ Seal

Arkivoc 2021, part x, 77-89

\title{
Fusing privileged structures: synthesis and characterization of new benzothiophene-chalcone hybrids
}

\author{
Elif Akin Kazancioglua,b \\ ${ }^{a}$ Vocational High School of Health Services Kilis 7 Aralik University, 79090, Kilis, Turkey \\ ${ }^{b}$ Advanced Technology Application and Research Center Kilis 7 Aralik University, 79090, Kilis, Turkey \\ Email: elifaakin@gmail.com
}

Received 09-06-2021

Accepted Manuscript 10-21-2021

Published on line 11-07-2021

\section{Abstract}

Chalcones form the core of a variety of medicinal compounds which possess a wide variety of cytoprotective and modulatory therapeutic potential for multiple disease states. A series of benzothiophene-chalcone hybrids were designed and prepared through the Claisen condensation of benzothiophene-substituted acetophenone with halogenated aldehydes. In some cases, products of aromatic substitution of halogen atom by methoxy group were obtained in addition to the expected condensation products. All new compounds were fully characterized.

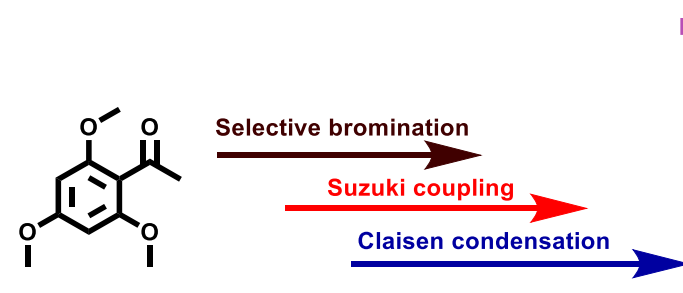

Hybrid benzothiophene

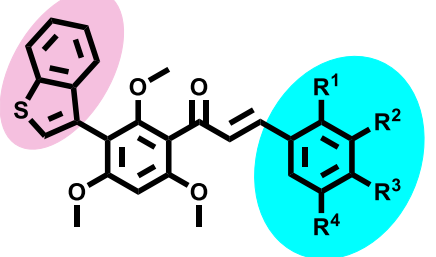

Rich halogen presence

$\mathrm{S}_{\mathrm{N}} \mathrm{Ar}$ reactions

Keywords: Benzothiophene, chalcone, bromination, Claisen-Schmidt condensation, Suzuki coupling reaction 


\section{Introduction}

Flavonoids are known to possess a broad spectrum of biological activities, and can be classified into flavones, flavon-3-ols, flavonols, isoflavones, flavones, anthocyanidins/anthocyanins, flavanones, homo-isoflavonoids, aurones and chalcones..$^{1-2}$ Chalcones are known as a subgroup of flavanoids, which possess an open-chain, $\alpha, \beta$ -unsaturated carbonyl group with two aromatic rings. Chalcone can be regarded as a privileged structure as it is found in many natural and synthetic compounds featuring a wide range of biological activities, including antimicrobial, antitumor, antioxidant, anti-inflammatory, anticonvulsant, anti-estrogenic and anticancer, etc. ${ }^{3}$ The chalcones' decreasing effect on free-radical formation may reduce DNA damage and the risk of mutagenicity. Also, most of the studies reported that chalcones induced apoptosis in the cancer-cell lines. ${ }^{3-4}$ This significant substructure possesses a pharmacophoric effect along with anticancer activity described in many studies. ${ }^{5-6}$

Although estrogen is primarily known as a reproductive hormone, it also displays many positive effects on the skeleton, cardiovascular and nervous systems. Despite these beneficial effects of estrogen, it is known that a high level of estrogen increases the risk of breast cancer. Estrogen is thought to play a role in the progression of many gynecological cancers, such as breast cancer and endometrial cancer. ${ }^{7}$ In gynecological cancers, the estrogen-receptor and the estrogen-biosynthetic enzyme activities are significantly increased compared to normal mammary-gland tissue. Therefore, it is important to selectively develop estrogen-receptor modulators that will protect their beneficial effects on the organs, but be inactive in the breast ${ }^{8}$ (Figure 1)

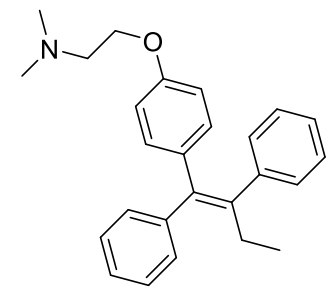

Tamoxifen

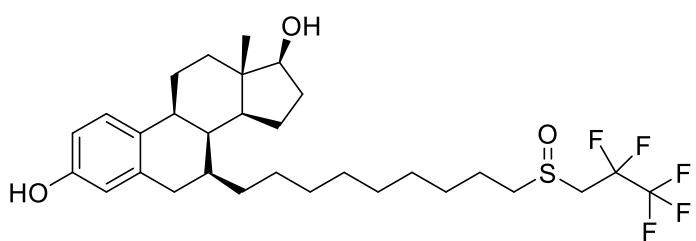

Fulvestrant

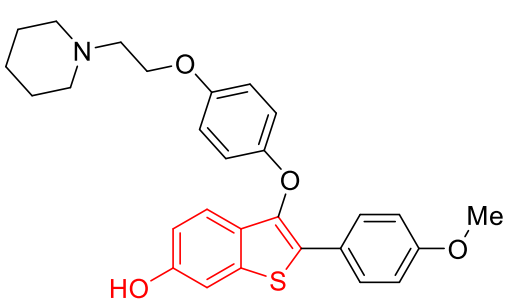

Arzoxifene

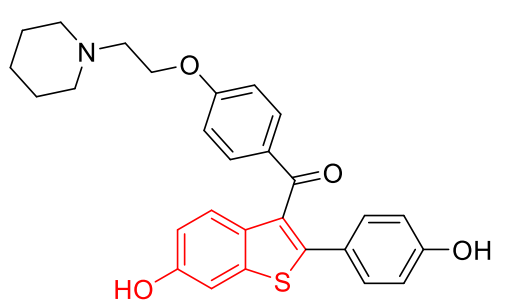

Raloxifen (LY139481)

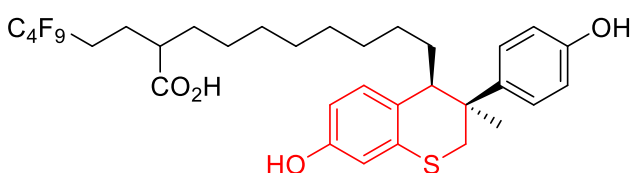

CH4986399

Figure 1. Representative selective estrogen receptor downregulators (SERDs) and selective estrogen receptor modulators (SERMs).

Tamoxifen has been used in the treatment of breast cancers since 1970 due to its anti-estrogenic effect. ${ }^{9}$ However, since drugs such as tamoxifen, a selective estrogen receptor modulator, and fulvestrant, a selective estrogen receptor downregulator, develop drug resistance in patients during treatment, the discovery of new drugs that are structurally different from these drugs is important. ${ }^{10-11}$ Benzothiophene derivatives and their salts, which have anti-estrogenic activity and are effective in gynecological cancers such as breast cancer, endometrial cancer, mastopathy, and endometriosis, can be cited as examples. ${ }^{11}$ Recently, compounds 
containing a benzothiophene skeletal structure, such as Raloxifene and Arzoxifene (Figure 2), have been used safely in the treatment of breast cancer. ${ }^{12}$<smiles>O=c1ccoc2ccccc12</smiles>

Flavone (4H-chromen-4-one)<smiles>O=c1ccsc2ccccc12</smiles>

Thioflavone<smiles>O=C1CCSc2ccccc21</smiles>
(4H-thiochromen-4-one)

Thioflavanone Thiochromon-4-one

Figure 2. Molecular structures of flavone, thioflavone, and thioflavanone.

Furthermore, thioflavonones (thiochromones) and their analogs are important skeletons and privileged scaffolds in medicinal chemistry. Yoneya et al. indicated that $\mathrm{CH} 4986399$ (previously shown in Figure 1) was effective in treating the partial tamoxifen-resistant ZR-75-1 xenograft and may be beneficial in the treatment of tamoxifen or fulvestrant-resistant tumors. ${ }^{12}$

Since sulfur-containing compounds are found less in nature, structures such as thioflavanones containing $S$ have been studied less in the literature. ${ }^{13}$ Marc et al. reported that they synthesized two series of chalcogen flavones, and reported that thioflavone derivatives had the highest inhibitory effect with the most effluxpump inhibition at the concentration of $2 \mathrm{mM}$. It was also noticed that flavanone induces apoptosis, and this may be a new approach for cancer therapy. ${ }^{14}$

Chalcones are common structural compounds and bioisosteres of flavones, and exhibit anti-cancer activity. ${ }^{15}$ Cyclization of chalcones gives the flavone, thiazines, pyrimidines, etc., that exhibit a wide range of biological activities. ${ }^{16}$ Mahapatra et al. declared that most of the chalcone derivatives might be of use in multidrug resistance as an inhibitor. Bischalcone, containing a methoxy group (-OMe), was found to be potent and selective against various drug-selected cancer cells. ${ }^{17}$

Han et. al. synthesized 2,4-dihydroxy groups and 2,4-dimethoxy groups on ring $A$ and a mono halogen on ring $B$ which were non-basic chalcone analogs that showed the most effective results on breast cancerresistance protein. ${ }^{18}$ Sharma et. al. indicated that biphenyl chalcones demonstrated a greater anti-cancer reaction than tamoxifen. ${ }^{19}$ (Figure 3 )
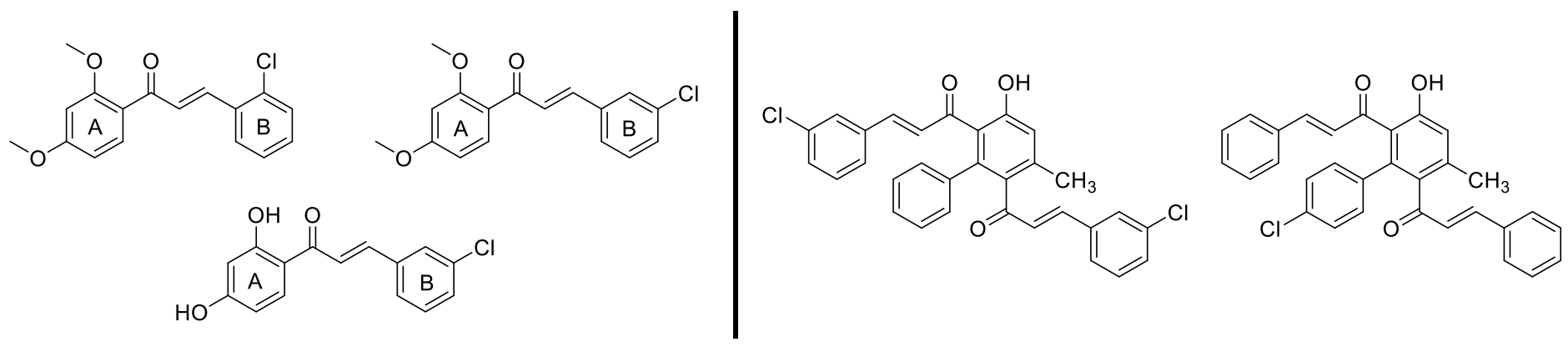

Figure 3. Chemical structure of some biologically-active chalcones for breast cancer.

Chalcones are important constituents of many natural products and drugs, and are generally divided into simple chalcones and biaryl/hybrid chalcones. As we mentioned previously, chalcones possess a broad range 
of biological activities. Furthermore, fusion with other pharmacophores or privileged scaffolds may improve and modulate the pharmaceutical features of chalcones such as selectivity, solubility and bioavailability. ${ }^{20}$

Molecular modification to increase the biological activity of target compounds is a standard method in drug development. In this work, the molecular modification method was used to design the chalcone derivatives as a combination of benzothiophene biphenyls and various halogenated benzaldehydes to synthesize the biaryl-chalcones through a two-step methodology comprised of a Suzuki coupling and ClaisenSchmidt condensation reaction. The resulting chalcones incorporate two biologically important structural features: (a) a benzothiophene fragment that is efficient in estrogenic cancers, and (b) halogen substituents in the $B$ ring of chalcone that are known to lead to higher anticancer potential. ${ }^{21-22}$ Although the number of natural compounds containing fluorine is scarce, the number of approved fluorine-containing drugs (c) is constantly increasing. ${ }^{23-24}$ The fluorine atom causes a minimal steric effect in a molecule in which it is inserted, while bringing significant changes in the activity of the molecule. Since it is a small atom, the molecule may interact better with the active site of the enzyme, receptor-recognition sites, and other biological systems. ${ }^{25}$ The small size and short length of the C-F bond make the C-F substitution very interesting. ${ }^{26}$

In this work, a series of novel benzothiophene-containing biaryl-based chalcone analogs were synthesized by condensing benzothiophene-substituted acetophenone with several aromatic aldehydes halogenated at various positions. It is envisaged that these thio-analogs may possess attractive antioxidant, antimicrobial, antitumor and anticancer properties.

\section{Results and Discussion}

Scheme 1 outlines the general synthetic route for preparing the starting material, benzothiophene-containing acetophenone. Initially, the 3-bromo-2,4,6-trimethoxyacetophenone (2) was synthesized from 2,4,6trimethoxyacetophenone (1) by the treatment with ammonium cerium (IV) nitrate (1 eq.) and $\mathrm{LiBr}$ (1 eq.) in $\mathrm{CH}_{3} \mathrm{CN}\left(2.5 \mathrm{~mL} / 1 \mathrm{mmol}\right.$ of the substrate) following the literature procedure ${ }^{2}$. The core structure benzothiophene substituted acetophenone (3) was obtained by Suzuki coupling reaction of 3-bromo-2,4,6trimethoxyacetophenone (2) and benzo[b]thien-3-ylboronic acid in 77\% yield. Although the acetophenone contains three methoxy group at the 2,4 and 6 positions, is a fairly bulky compound, no steric obstacle has occurred, and the reaction was successfully carried out with benzo[b]thien-3-ylboronic acid via Suzuki Coupling reaction.

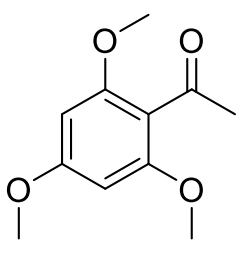

1

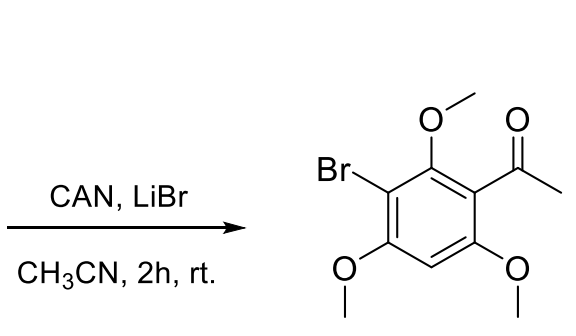

2

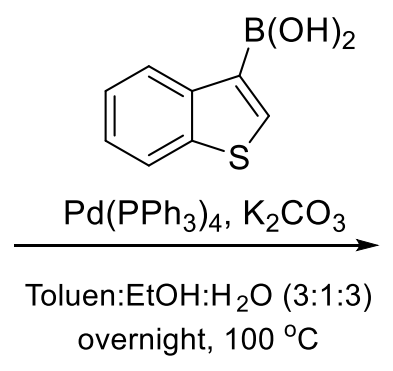

overnight, $100^{\circ} \mathrm{C}$

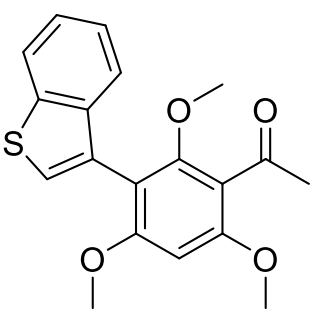

3

Scheme 1. The synthesis of benzothiophene-substituted acetophenone (3). 
Next, benzothiophene-containing biaryl-based chalcones were synthesized according to Scheme 2 via a base-promoted Claisen-Schmidt condensation reaction. Acetophenone, chloro- or fluoro-substituted aldehydes and aqueous $\mathrm{KOH}(50 \%)$ were dissolved in methanol at room temperature and stirred overnight. After completion of the reaction (according to the TLC), the reaction mixture was extracted and purified by column chromatography, yielding the target compounds. Structural analyses of all chalcone derivatives were performed by MP, IR, HRMS, ${ }^{1} \mathrm{H}$, and ${ }^{13} \mathrm{C}$ NMR methods. In ${ }^{1} \mathrm{H}-\mathrm{NMR}$, the disappearance of the acetophenone' acyl protons $\left(-\mathrm{COCH}_{3}\right)$, appearance as the singlet proton of compound 3' $-\mathrm{COCH}_{3}$ at $2.5 \mathrm{ppm}$, and appearance of the double-bond protons of the unsaturated carbonyl group as doublets $(J 16.0 \mathrm{MHz})$ at 7.45 and $7.05 \mathrm{ppm}$, respectively, showed that chalcone structures were formed.

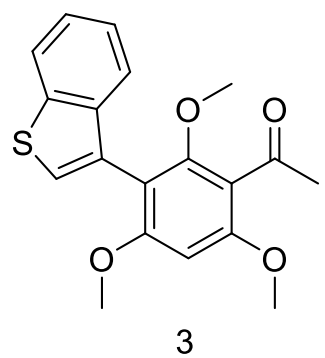

3

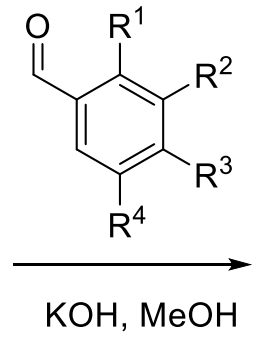

4: $\mathrm{R}^{1}=\mathrm{R}^{2}=\mathrm{R}^{3}=\mathrm{R}^{4}=\mathrm{H}$

5: $\mathrm{R}^{1}=\mathrm{Cl}, \mathrm{R}^{2}=\mathrm{R}^{3}=\mathrm{R}^{4}=\mathrm{H}$

6: $\mathrm{R}^{1}=\mathrm{R}^{3}=\mathrm{R}^{4}=\mathrm{H}, \mathrm{R}^{2}=\mathrm{Cl}$

7: $\mathrm{R}^{1}=\mathrm{R}^{2}=\mathrm{R}^{4}=\mathrm{H}, \mathrm{R}^{3}=\mathrm{Cl}$

8: $R^{1}=F, R^{2}=R^{3}=R^{4}=H$

9: $\mathrm{R}^{1}=\mathrm{OMe}, \mathrm{R}^{2}=\mathrm{R}^{3}=\mathrm{R}^{4}=\mathrm{H}$

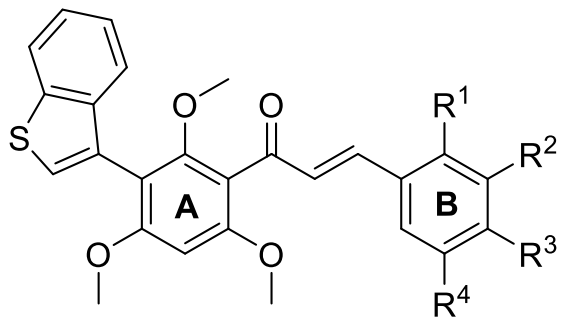

10: $R^{1}=R^{3}=R^{4}=H, R^{2}=F$

11: $R^{1}=R^{2}=R^{4}=H, R^{3}=F$

12: $R^{1}=R^{2}=R^{4}=H, R^{3}=O M e$

13: $R^{1}=R^{4}=F, R^{2}=H, R^{3}=O M e$

14: $R^{1}=R^{3}=O M e, R^{2}=H, R^{4}=F$

Scheme 2. Benzothiophene-containing biaryl-based chalcone derivatives.

The Claisen-Schmidt condensation reaction takes place in methanol under basic condition and, thus, methoxide anion is formed in the reaction media. When the reaction outcome was examined, it was found that, in several instances, the methoxide anion behaves both as a base and as a nucleophile, displacing fluorine through an $S_{N} A r$ reaction. The $S_{N} A r$ reactions are believed to occur through the sequence of addition and elimination steps as shown in Scheme 3.
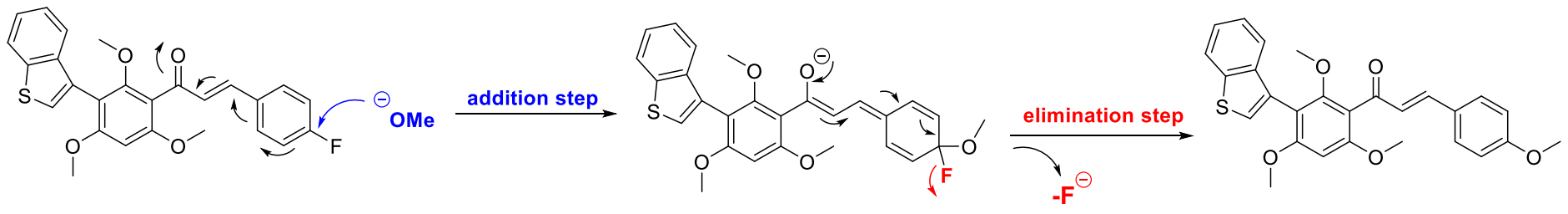

Scheme 3. $S_{N} A r$ reaction mechanism.

Looking at the elimination rates, the elimination rate of $\mathrm{F}$ is $10^{2}-10^{3}$ times faster than $\mathrm{Cl}$ and $\mathrm{Br}$ atoms. ${ }^{27}$ This explains how fast $\mathrm{F}$ elimination has occurred in the reaction even at room temperature. When the reaction times were prolonged, it was observed that elimination takes place only in fluorine-substituted molecules and not in the chlorine-substituted ones. Table 1 summarizes the products and yields. 
Table 1. Claisen-Schmidt condensation and $S_{N} A r$ products

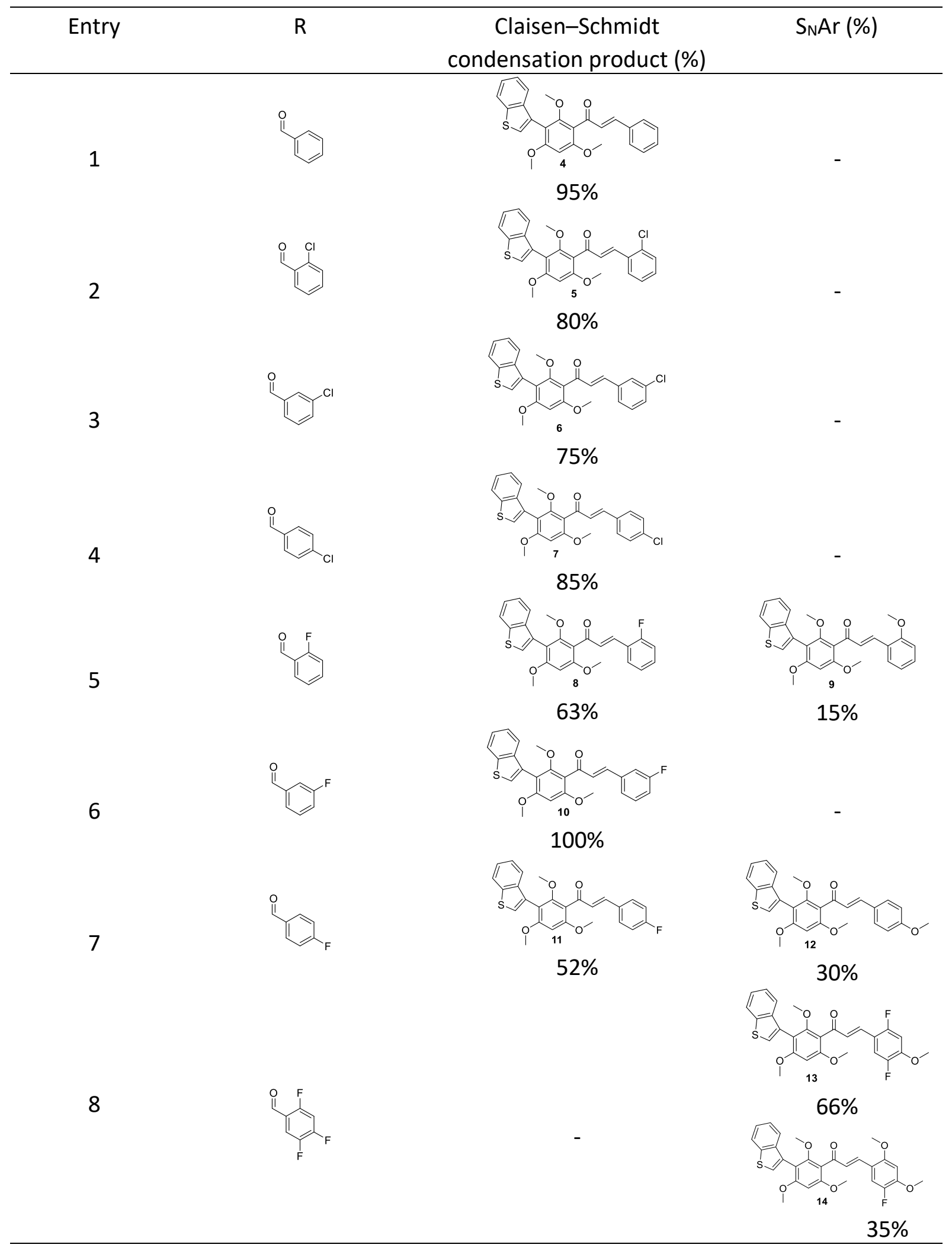




\section{Conclusions}

Benzothiophene-containing biaryl-based chalcone analogs were synthesized in overall high yields. Aromatic substitution occurred in fluoro-substituted compounds from both ortho- and para-positions, increasing the overall diversity of products using our strategy. Overall, our method has several advantages, including i) readily available starting material, ii) high yields, iii) modifiable target compounds, and iv) robustness and operational simplicity. Hence this process can be employed for the convenient synthesis of biaryl-based chalcone derivatives. Thiophene derivatives of the eleven new hybrid chalcones were synthesized and characterized. These new benzothiophene-containing, biaryl-based chalcone derivatives may find application as effective alternatives to known agents for treating gynecologic cancers.

\section{Experimental Section}

General. All reagents used were commercially available unless otherwise specified and all solvents were distilled before use. Melting points were measured with Stuart SMP20 melting point devices. IR Spectra: PerkinElmer Spectrum One FT-IR spectrometer. ${ }^{1} \mathrm{H}$ and ${ }^{13} \mathrm{C}$ NMR Spectra: Bruker 600 spectrometers. Chemical shift values are expressed in $\delta(\mathrm{ppm})$ relative to tetramethyl silane $\left(\mathrm{TMS}, \delta=0.00 \mathrm{ppm}\right.$ for ${ }^{1} \mathrm{H}$ NMR and $\delta=$ $77.0 \mathrm{ppm}$ for ${ }^{13} \mathrm{C} \mathrm{NMR}$ ). Data are reported as follows: chemical shift, multiplicity ( $\mathrm{s}=$ singlet, $\mathrm{d}=\mathrm{doublet}, \mathrm{t}=$ triplet, $q=$ quartet, $\mathrm{m}=$ multiplet), coupling constants $(\mathrm{Hz})$, and integration. HRMS were recorded on a Quadrupole time-of-flight (QTOF) instrument.

1-(3-(Benzo[b]thiophen-3-yl)-2,4,6-trimethoxyphenyl)ethan-1-one (3). 1-(3-bromo-2,4,6-trimethoxyphenyl)ethan-1-one (2) $(2.20 \mathrm{~g}, 7.61 \mathrm{mmol})$ and benzo[b]thien-3-ylboronic acid $(1.76 \mathrm{~g}, 9.89 \mathrm{mmol})$ were dissolved in a solvent system of toluene $(30 \mathrm{~mL})$ and $\mathrm{EtOH}(10 \mathrm{~mL}) . \mathrm{Pd}\left(\mathrm{PPh}_{3}\right)_{4}(0.22 \mathrm{~g}, 0.19 \mathrm{mmol})$ was added followed by aq. $\mathrm{K}_{2} \mathrm{CO}_{3}\left(2.63 \mathrm{~g}\right.$ dissolved in $30 \mathrm{~mL} \mathrm{H} \mathrm{H}_{2} \mathrm{O}, 19.3 \mathrm{mmol}$ ). The reaction mixture was refluxed for overnight. Solvents were concentrated under vacuum and the crude product was extracted with EtOAc and brine. The organic layer was dried over $\mathrm{Na}_{2} \mathrm{SO}_{4}$, filtered and concentrated under vacuum. The remaining residue was purified via column chromatography over silica gel using gradient elution with EtOAc:hexanes (1:9) to yield compound 3 as a white solid $(2.0 \mathrm{~g})$ Yield: $77 \%, R_{f}\left(\right.$ EtOAc/Hexanes 1:9) $=0.15 . \mathrm{mp} 68-70{ }^{\circ} \mathrm{C} . I R\left(V_{\max }, \mathrm{cm}^{-1}\right)$ : 2930, 1706, 1591, 1463, 1374, 1273, 1204, 1105. ${ }^{1} \mathrm{H}$ NMR $\left(600 \mathrm{MHz}, \mathrm{CDCl}_{3}\right) \delta 7.94-7.88(\mathrm{~m}, 1 \mathrm{H}, \mathrm{CH}), 7.49-$ $7.44(\mathrm{~m}, 1 \mathrm{H}, \mathrm{CH}), 7.41(\mathrm{~s}, 1 \mathrm{H}, \mathrm{CH}), 7.39-7.31(\mathrm{~m}, 2 \mathrm{H}, \mathrm{CH}), 6.40(\mathrm{~s}, 1 \mathrm{H}, \mathrm{CH}), 3.93\left(\mathrm{~s}, 3 \mathrm{H}, \mathrm{OCH}_{3}\right), 3.75(\mathrm{~s}, 3 \mathrm{H}$, $\left.\mathrm{OCH}_{3}\right), 3.24\left(\mathrm{~s}, 3 \mathrm{H}, \mathrm{OCH}_{3}\right), 2.57\left(\mathrm{~s}, 3 \mathrm{H}, \mathrm{CH}_{3}\right) .{ }^{13} \mathrm{C} \mathrm{NMR}\left(150 \mathrm{MHz}, \mathrm{CDCl}_{3}\right) \delta 201.9(\mathrm{CO}), 160.1(\mathrm{CH}), 157.4(\mathrm{CH})$, $157.3(\mathrm{CH}), 139.4(\mathrm{CH}), 139.1(\mathrm{CH}), 128.5(\mathrm{CH}), 125.8(\mathrm{CH}), 124.1(\mathrm{CH}), 123.9(\mathrm{CH}), 123.3(\mathrm{CH}), 122.5(\mathrm{CH}), 118.9$ $(\mathrm{CH}), 110.5(\mathrm{CH}), 91.3(\mathrm{CH}), 61.9\left(\mathrm{OCH}_{3}\right), 2 \times 55.9\left(\mathrm{OCH}_{3}\right), 32.7\left(\mathrm{CH}_{3}\right)$.

(E)-1-(3-(Benzo[b]thiophen-3-yl)-2,4,6-trimethoxyphenyl)-3-phenylprop-2-en-1-one (4). To a solution of 1-(3(benzo[b]thiophen-3-yl)-2,4,6-trimethoxyphenyl)ethan-1-one (3) (78 mg, $0.23 \mathrm{mmol}$ ) in methanol (2 mL) was mixed in benzaldehyde ( $41 \mu \mathrm{L}, 0.36 \mathrm{mmol}$ ) and $\mathrm{KOH}$ ( $50 \%$ in water solution, $2 \mathrm{~mL}$ ). After stirring for $24 \mathrm{~h}$ at rt, the solvent was removed under vacuum and the mixture was extracted with saturated $\mathrm{NH}_{4} \mathrm{Cl}$ solution and $\mathrm{CH}_{2} \mathrm{Cl}_{2}$, and dried over $\mathrm{Na}_{2} \mathrm{SO}_{4}$. The crude material was purified via column chromatography over silica gel using gradient elution with EtOAc/hexanes (10:90) to yield 4 as a yellow solid (94.1 $\mathrm{mg}, 95 \%)$. $\mathrm{R}_{\mathrm{f}}$

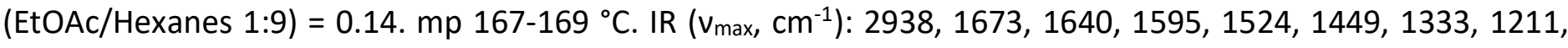
1101. ${ }^{1} \mathrm{H}$ NMR $\left(600 \mathrm{MHz}^{\mathrm{CDCl}}{ }_{3}\right) \delta 7.89$ (dd, J 6.5, $\left.2.2 \mathrm{~Hz}, 1 \mathrm{H}, \mathrm{CH}\right), 7.57$ (dd, J 6.5, $\left.2.8 \mathrm{~Hz}, 2 \mathrm{H}, \mathrm{CH}\right), 7.51-7.48$ $(\mathrm{m}, 1 \mathrm{H}, \mathrm{CH}), 7.45(\mathrm{~d}, J 16.0 \mathrm{~Hz}, 1 \mathrm{H}, \mathrm{CH}), 7.41-7.37(\mathrm{~m}, 3 \mathrm{H}, \mathrm{CH}), 7.37-7.31(\mathrm{~m}, 2 \mathrm{H}, \mathrm{CH}), 7.05(\mathrm{~d}, J 16.1 \mathrm{~Hz}, 1 \mathrm{H}$, 
$\mathrm{CH}), 6.44(\mathrm{~s}, 1 \mathrm{H}, \mathrm{CH}), 3.89\left(\mathrm{~s}, 3 \mathrm{H}, \mathrm{OCH}_{3}\right), 3.77\left(\mathrm{~s}, 3 \mathrm{H}, \mathrm{OCH}_{3}\right), 3.21\left(\mathrm{~s}, 3 \mathrm{H}, \mathrm{OCH}_{3}\right) .{ }^{13} \mathrm{C} \mathrm{NMR}\left(150 \mathrm{MHz}^{\mathrm{CDCl}}\right)_{3} \delta$ $194.3(\mathrm{CO}), 160.2(\mathrm{CH}), 158.1(\mathrm{CH}), 158.0(\mathrm{CH}), 144.9(\mathrm{CH}), 139.4(\mathrm{CH}), 139.0(\mathrm{CH}), 134.8(\mathrm{CH}), 130.4(\mathrm{CH})$, $128.9(\mathrm{CH}), 128.8(\mathrm{CH}), 128.5(\mathrm{CH}), 128.5(\mathrm{CH}), 125.8(\mathrm{CH}), 124.0(\mathrm{CH}), 123.9(\mathrm{CH}), 123.3(\mathrm{CH}), 122.5(\mathrm{CH}), 116.7$ $(\mathrm{CH}), 110.4(\mathrm{CH}), 91.4(\mathrm{CH}), 61.8\left(\mathrm{OCH}_{3}\right), 56.0\left(\mathrm{OCH}_{3}\right), 55.9\left(\mathrm{OCH}_{3}\right) . \mathrm{HRMS}(\mathrm{ESI}-\mathrm{TOF}): \mathrm{m} / \mathrm{z}[\mathrm{M}+\mathrm{H}]^{+}$calculated for $\mathrm{C}_{26} \mathrm{H}_{23} \mathrm{O}_{4} \mathrm{~S}, 431.1317$; found, 431.1286.

(E)-1-(3-(Benzo[b]thiophen-3-yl)-2,4,6-trimethoxyphenyl)-3-(2-chlorophenyl)prop-2-en-1-one (5). To a solution of 1-(3-(benzo[b]thiophen-3-yl)-2,4,6-trimethoxyphenyl)ethan-1-one (3) (88 $\mathrm{mg}, 0.26 \mathrm{mmol}$ ) in methanol $(2 \mathrm{~mL}$ ) was mixed in 2-chlorobenzaldehyde $(46 \mu \mathrm{L}, 0.41 \mathrm{mmol})$ and $\mathrm{KOH}(50 \%$ in water solution, 2 $\mathrm{mL}$ ). After stirring for $24 \mathrm{~h}$ at $\mathrm{rt}$, the solvent was removed under vacuum and the mixture was extracted with saturated $\mathrm{NH}_{4} \mathrm{Cl}$ solution and $\mathrm{CH}_{2} \mathrm{Cl}_{2}$, and dried over $\mathrm{Na}_{2} \mathrm{SO}_{4}$. The crude material was purified via column chromatography over silica gel using gradient elution with EtOAc/hexanes (20:80) to yield $\mathbf{5}$ as a yellow solid (97 mg, 80\%). Rf $\left(\right.$ EtOAc/Hexanes 2:8) = 0.2. $\mathrm{mp} \mathrm{140-142}{ }^{\circ} \mathrm{C} . \mathrm{IR}\left(\mathrm{V}_{\max }, \mathrm{cm}^{-1}\right): 2922,1661,1602,1531,1464$, 1398, 1268, 1215, 1106. ${ }^{1} \mathrm{H}$ NMR $\left(600 \mathrm{MHz}, \mathrm{CDCl}_{3}\right) \delta 7.93-7.85(\mathrm{~m}, 2 \mathrm{H}, \mathrm{CH}), 7.71(\mathrm{dd}, J \mathrm{~J} .1,2.0 \mathrm{~Hz}, 1 \mathrm{H}, \mathrm{CH})$, $7.52-7.47(\mathrm{~m}, 1 \mathrm{H}, \mathrm{CH}), 7.44-7.39(\mathrm{~m}, 2 \mathrm{H}, \mathrm{CH}), 7.37-7.27(\mathrm{~m}, 4 \mathrm{H}, \mathrm{CH}), 7.00(\mathrm{~d}, J 16.1 \mathrm{~Hz}, 1 \mathrm{H}, \mathrm{CH}), 6.44(\mathrm{~s}, 1 \mathrm{H}$, $\mathrm{CH}), 3.90\left(\mathrm{~s}, 3 \mathrm{H}, \mathrm{OCH}_{3}\right), 3.77\left(\mathrm{~s}, 3 \mathrm{H}, \mathrm{OCH}_{3}\right), 3.21\left(\mathrm{~s}, 3 \mathrm{H}, \mathrm{OCH}_{3}\right) .{ }^{13} \mathrm{C} \mathrm{NMR}\left(150 \mathrm{MHz} \mathrm{CDCl}_{3}\right) \delta 194.3(\mathrm{CO}), 160.3$ $(\mathrm{CH}), 158.1(\mathrm{CH}), 158.0(\mathrm{CH}), 140.8(\mathrm{CH}), 139.4(\mathrm{CH}), 139.1(\mathrm{CH}), 135.1(\mathrm{CH}), 133.0(\mathrm{CH}), 131.1(\mathrm{CH}), 131.0(\mathrm{CH})$, $130.1(\mathrm{CH}), 128.5(\mathrm{CH}), 127.8(\mathrm{CH}), 127.1(\mathrm{CH}), 125.8(\mathrm{CH}), 124.1(\mathrm{CH}), 124.0(\mathrm{CH}), 123.3(\mathrm{CH}), 122.5(\mathrm{CH}), 116.2$ $(\mathrm{CH}), 110.3(\mathrm{CH}), 91.3(\mathrm{CH}), 61.9\left(\mathrm{OCH}_{3}\right), 56.0\left(\mathrm{OCH}_{3}\right), 55.9\left(\mathrm{OCH}_{3}\right) . \mathrm{HRMS}(\mathrm{ESI}-\mathrm{TOF}): \mathrm{m} / \mathrm{z}[\mathrm{M}+\mathrm{H}]^{+}$calculated for $\mathrm{C}_{26} \mathrm{H}_{22} \mathrm{ClO}_{4} \mathrm{~S}, 465.0927$; found, 465.0900.

(E)-1-(3-(Benzo[b]thiophen-3-yl)-2,4,6-trimethoxyphenyl)-3-(3-chlorophenyl)prop-2-en-1-one (6). To a solution of 1-(3-(benzo[b]thiophen-3-yl)-2,4,6-trimethoxyphenyl)ethan-1-one (3) (88 $\mathrm{mg}, 0.26 \mathrm{mmol}$ ) in methanol $(2 \mathrm{~mL}$ ) was mixed in 3-chlorobenzaldehyde $(46 \mu \mathrm{L}, 0.41 \mathrm{mmol})$ and $\mathrm{KOH}(50 \%$ in water solution, 2 $\mathrm{mL}$ ). After stirring for $24 \mathrm{~h}$ at $\mathrm{rt}$, the solvent was removed under vacuum and the mixture was extracted with saturated $\mathrm{NH}_{4} \mathrm{Cl}$ solution and $\mathrm{CH}_{2} \mathrm{Cl}_{2}$, and dried over $\mathrm{Na}_{2} \mathrm{SO}_{4}$. The crude material was purified via column chromatography over silica gel using gradient elution with EtOAc/hexanes (10:90) to yield 6 as a yellow solid (91 mg, 75\%). $R_{f}\left(\right.$ EtOAc/Hexanes 1:9) = $0.13 \mathrm{mp} 164-165^{\circ} \mathrm{C} \mathrm{IR}\left(V_{\max }, \mathrm{cm}^{-1}\right): 2922,1671,1599,1455,1310,1197$, 1105. ${ }^{1} \mathrm{H}$ NMR $\left(600 \mathrm{MHz}, \mathrm{CDCl}_{3}\right) \delta 7.91-7.87(\mathrm{~m}, 1 \mathrm{H}, \mathrm{CH}), 7.54(\mathrm{~s}, 1 \mathrm{H}, \mathrm{CH}), 7.49-7.46(\mathrm{~m}, 1 \mathrm{H}, \mathrm{CH}), 7.46-7.39$ $(\mathrm{m}, 3 \mathrm{H}, \mathrm{CH}), 7.37-7.30(\mathrm{~m}, 4 \mathrm{H}, \mathrm{CH}), 7.03(\mathrm{~d}, \mathrm{~J} 16.1 \mathrm{~Hz}, 1 \mathrm{H}, \mathrm{CH}), 6.43(\mathrm{~s}, 1 \mathrm{H}, \mathrm{CH}), 3.89\left(\mathrm{~s}, 3 \mathrm{H}, \mathrm{OCH}_{3}\right), 3.77(\mathrm{~s}, 3 \mathrm{H}$, $\left.\mathrm{OCH}_{3}\right), 3.20\left(\mathrm{~s}, 3 \mathrm{H}, \mathrm{OCH}_{3}\right) .{ }^{13} \mathrm{C} \mathrm{NMR}\left(150 \mathrm{MHz}_{\mathrm{CDCl}}\right.$ ) $\delta 193.7(\mathrm{CO}), 160.4(\mathrm{CH}), 158.1(\mathrm{CH}), 158.1(\mathrm{CH}), 142.7$ $(\mathrm{CH}), 139.4(\mathrm{CH}), 139.0(\mathrm{CH}), 136.7(\mathrm{CH}), 134.8(\mathrm{CH}), 130.1(\mathrm{CH}), 130.1(\mathrm{CH}), 129.9(\mathrm{CH}), 128.4(\mathrm{CH}), 128.2(\mathrm{CH})$, $126.5(\mathrm{CH}), 125.8(\mathrm{CH}), 124.1(\mathrm{CH}), 123.9(\mathrm{CH}), 123.2(\mathrm{CH}), 122.6(\mathrm{CH}), 116.5(\mathrm{CH}), 110.4(\mathrm{CH}), 91.3(\mathrm{CH}), 61.9$ $\left(\mathrm{OCH}_{3}\right), 56.0\left(\mathrm{OCH}_{3}\right), 55.9\left(\mathrm{OCH}_{3}\right)$. HRMS (ESI-TOF): $\mathrm{m} / z[\mathrm{M}+\mathrm{H}]^{+}$calculated for $\mathrm{C}_{26} \mathrm{H}_{22} \mathrm{ClO} \mathrm{O}_{4} \mathrm{~S}, 465.0927$; found, 465.0887.

(E)-1-(3-(Benzo[b]thiophen-3-yl)-2,4,6-trimethoxyphenyl)-3-(4-chlorophenyl)prop-2-en-1-one (7). To a solution of 1-(3-(benzo[b]thiophen-3-yl)-2,4,6-trimethoxyphenyl)ethan-1-one (3) (100 $\mathrm{mg}, 0.29 \mathrm{mmol})$ in methanol $(3 \mathrm{~mL})$ was mixed in 4-chlorobenzaldehyde $(65.7 \mathrm{mg}, 0.47 \mathrm{mmol})$ and $\mathrm{KOH}(50 \%$ in water solution, 2 $\mathrm{mL}$ ). After stirring for $24 \mathrm{~h}$ at $\mathrm{rt}$, the solvent was removed under vacuum and the mixture was extracted with saturated $\mathrm{NH}_{4} \mathrm{Cl}$ solution and $\mathrm{CH}_{2} \mathrm{Cl}_{2}$, and dried over $\mathrm{Na}_{2} \mathrm{SO}_{4}$. The crude material was purified via column chromatography over silica gel using gradient elution with EtOAc/hexanes (10:90) to yield 7 as a light-yellow

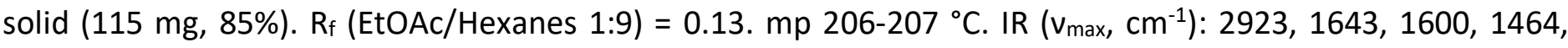

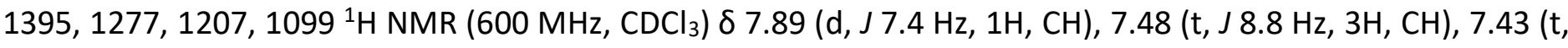
J $8.0 \mathrm{~Hz}, 2 \mathrm{H}, \mathrm{CH}), 7.38-7.31(\mathrm{~m}, 4 \mathrm{H}, \mathrm{CH}), 7.02(\mathrm{~d}, J 16.1 \mathrm{~Hz}, 1 \mathrm{H}, \mathrm{CH}), 6.44(\mathrm{~s}, 1 \mathrm{H}, \mathrm{CH}), 3.89(\mathrm{~s}, 3 \mathrm{H}, \mathrm{OCH}), 3.77$ $\left(\mathrm{s}, 3 \mathrm{H}, \mathrm{OCH}_{3}\right), 3.20\left(\mathrm{~s}, 3 \mathrm{H}, \mathrm{OCH}_{3}\right) \cdot{ }^{13} \mathrm{C} \mathrm{NMR}\left(150 \mathrm{MHz}, \mathrm{CDCl}_{3}\right) \delta 193.9(\mathrm{CO}), 160.3(\mathrm{CH}), 158.1(\mathrm{CH}), 158.0(\mathrm{CH})$, $143.1(\mathrm{CH}), 139.4(\mathrm{CH}), 139.0(\mathrm{CH}), 136.2(\mathrm{CH}), 133.3(\mathrm{CH}), 129.6(\mathrm{CH}), 129.2(\mathrm{CH}), 129.1(\mathrm{CH}), 128.4(\mathrm{CH}), 125.8$ 
(CH), $124.1(\mathrm{CH}), 123.9(\mathrm{CH}), 123.2(\mathrm{CH}), 122.6(\mathrm{CH}), 116.6(\mathrm{CH}), 110.4(\mathrm{CH}), 91.4(\mathrm{CH}), 61.9\left(\mathrm{OCH}_{3}\right), 56.0$ $\left(\mathrm{OCH}_{3}\right), 55.9\left(\mathrm{OCH}_{3}\right)$. HRMS (ESI-TOF): $\mathrm{m} / z[\mathrm{M}+\mathrm{H}]^{+}$calculated for $\mathrm{C}_{26} \mathrm{H}_{22} \mathrm{ClO}_{4} \mathrm{~S}, 465.0927$; found, 465.0894.

(E)-1-(3-(Benzo[b]thiophen-3-yl)-2,4,6-trimethoxyphenyl)-3-(2-fluorophenyl)prop-2-en-1-one (8). To a solution of 1-(3-(benzo[b]thiophen-3-yl)-2,4,6-trimethoxyphenyl)ethan-1-one (3) (100 $\mathrm{mg}, 0.29 \mathrm{mmol})$ in methanol $(3 \mathrm{~mL}$ ) was mixed in 2-fluorobenzaldehyde $(50 \mu \mathrm{L}, 0.47 \mathrm{mmol})$ and $\mathrm{KOH}(50 \%$ in water solution, 2 $\mathrm{mL}$ ). After stirring for $24 \mathrm{~h}$ at $\mathrm{rt}$, the solvent was removed under vacuum and the mixture was extracted with saturated $\mathrm{NH}_{4} \mathrm{Cl}$ solution and $\mathrm{CH}_{2} \mathrm{Cl}_{2}$, and dried over $\mathrm{Na}_{2} \mathrm{SO}_{4}$. The crude material was purified via column chromatography over silica gel using gradient elution with EtOAc/hexanes (20:80) to yield 8 as a yellow solid

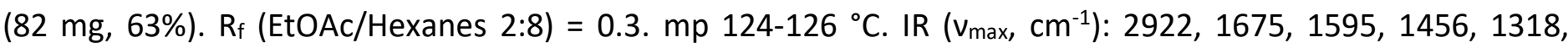
1274, 1210, 1100. ${ }^{1} \mathrm{H}$ NMR (600 MHz, $\left.\mathrm{CDCl}_{3}\right) \delta 7.91-7.87(\mathrm{~m}, 1 \mathrm{H}, \mathrm{CH}), 7.66-7.58(\mathrm{~m}, 2 \mathrm{H}, \mathrm{CH}), 7.52-7.47(\mathrm{~m}$, $1 \mathrm{H}, \mathrm{CH}), 7.43(\mathrm{~s}, 1 \mathrm{H}, \mathrm{CH}), 7.40-7.30(\mathrm{~m}, 3 \mathrm{H}, \mathrm{CH}), 7.17(\mathrm{t}, J 7.6 \mathrm{~Hz}, 1 \mathrm{H}, \mathrm{CH}), 7.10(\mathrm{dd}, J 17.5,7.6 \mathrm{~Hz}, 2 \mathrm{H}, \mathrm{CH})$, $6.44(\mathrm{~s}, 1 \mathrm{H}, \mathrm{CH}), 3.89\left(\mathrm{~s}, 3 \mathrm{H}, \mathrm{OCH}_{3}\right), 3.77\left(\mathrm{~s}, 3 \mathrm{H}, \mathrm{OCH}_{3}\right), 3.20\left(\mathrm{~s}, 3 \mathrm{H}, \mathrm{OCH}_{3}\right) .{ }^{13} \mathrm{C} \mathrm{NMR}\left(150 \mathrm{MHz}, \mathrm{CDCl}_{3}\right) \delta 194.3$ (CO), $162.2(\mathrm{CH}), 160.5(\mathrm{CH}), 160.3(\mathrm{CH}), 158.1(\mathrm{CH}), 158.0(\mathrm{CH}), 139.4(\mathrm{CH}), 139.0(\mathrm{CH}), 137.0(\mathrm{CH}), 137.0(\mathrm{CH})$, $131.8(\mathrm{CH}), 131.8(\mathrm{CH}), 130.7(\mathrm{CH}), 130.8(\mathrm{CH}), 128.9(\mathrm{CH}), 128.8(\mathrm{CH}), 128.5(\mathrm{CH}), 125.8(\mathrm{CH}), 124.5(\mathrm{CH}), 124.4$ $(\mathrm{CH}), 124.0(\mathrm{CH}), 123.9(\mathrm{CH}), 123.3(\mathrm{CH}), 122.9(\mathrm{CH}), 122.9(\mathrm{CH}), 122.5(\mathrm{CH}), 116.4(\mathrm{CH}), 116.2(\mathrm{CH}), 116.0(\mathrm{CH})$, $110.3(\mathrm{CH}), 91.4(\mathrm{CH}), 61.8\left(\mathrm{OCH}_{3}\right), 56.0\left(\mathrm{OCH}_{3}\right), 55.9\left(\mathrm{OCH}_{3}\right)$. HRMS (ESI-TOF): $\mathrm{m} / \mathrm{z}[\mathrm{M}+\mathrm{H}]^{+}$calculated for $\mathrm{C}_{26} \mathrm{H}_{22} \mathrm{FO}_{4} \mathrm{~S}, 449.1223$; found, 449.1184.

(E)-1-(3-(Benzo[b]thiophen-3-yl)-2,4,6-trimethoxyphenyl)-3-(2-methoxyphenyl)prop-2-en-1-one (9). To a solution of 1-(3-(benzo[b]thiophen-3-yl)-2,4,6-trimethoxyphenyl)ethan-1-one (3) (100 $\mathrm{mg}, 0.29 \mathrm{mmol})$ in methanol $(3 \mathrm{~mL}$ ) was mixed in 2-fluorobenzaldehyde $(50 \mu \mathrm{L}, 0.47 \mathrm{mmol}$ ) and $\mathrm{KOH}$ ( $50 \%$ in water solution, 2 $\mathrm{mL}$ ). After stirring for $24 \mathrm{~h}$ at $\mathrm{rt}$, the solvent was removed under vacuum and the mixture was extracted with saturated $\mathrm{NH}_{4} \mathrm{Cl}$ solution and $\mathrm{CH}_{2} \mathrm{Cl}_{2}$, and dried over $\mathrm{Na}_{2} \mathrm{SO}_{4}$. The crude material was purified via column chromatography over silica gel using gradient elution with EtOAc/hexanes (20:80) to yield 9 as a viscous liquid (20 mg, 15\%). $R_{f}\left(\right.$ EtOAc/Hexanes 2:8) = 0.2. IR $\left(v_{\max }, \mathrm{cm}^{-1}\right): 2922,1643,1596,1460,1331,1246,1107 .{ }^{1} \mathrm{H}$ NMR $\left(600 \mathrm{MHz}, \mathrm{CDCl}_{3}\right) \delta 7.89(\mathrm{~d}, 7.8 \mathrm{~Hz}, 1 \mathrm{H}, \mathrm{CH}), 7.81(\mathrm{~d}, J 16.2 \mathrm{~Hz}, 1 \mathrm{H}, \mathrm{CH}), 7.58(\mathrm{~d}, J 7.6 \mathrm{~Hz}, 1 \mathrm{H}, \mathrm{CH}), 7.52(\mathrm{~d}, J 7.4$ $\mathrm{Hz}, 1 \mathrm{H}, \mathrm{CH}), 7.43(\mathrm{~s}, 1 \mathrm{H}, \mathrm{CH}), 7.39-7.30(\mathrm{~m}, 3 \mathrm{H}, \mathrm{CH}), 7.10(\mathrm{~d}, J 16.3 \mathrm{~Hz}, 1 \mathrm{H}, \mathrm{CH}), 6.96(\mathrm{t}, J 7.5 \mathrm{~Hz}, 1 \mathrm{H}, \mathrm{CH}), 6.90$ $(\mathrm{d}, J 8.3 \mathrm{~Hz}, 1 \mathrm{H}, \mathrm{CH}), 6.44(\mathrm{~s}, 1 \mathrm{H}, \mathrm{CH}), 3.88\left(\mathrm{~s}, 3 \mathrm{H}, \mathrm{OCH}_{3}\right), 3.86\left(\mathrm{~s}, 3 \mathrm{H}, \mathrm{OCH}_{3}\right), 3.77\left(\mathrm{~s}, 3 \mathrm{H}, \mathrm{OCH}_{3}\right), 3.20(\mathrm{~s}, 3 \mathrm{H}$, $\left.\mathrm{OCH}_{3}\right) .{ }^{13} \mathrm{C}$ NMR $\left(150 \mathrm{MHz}, \mathrm{CDCl}_{3}\right) \delta 195.1(\mathrm{CO}), 160.0(\mathrm{CH}), 158.4(\mathrm{CH}), 158.0(\mathrm{CH}), 157.8(\mathrm{CH}), 140.7(\mathrm{CH})$, $139.4(\mathrm{CH}), 139.1(\mathrm{CH}), 131.7(\mathrm{CH}), 129.3(\mathrm{CH}), 128.8(\mathrm{CH}), 128.7(\mathrm{CH}), 125.7(\mathrm{CH}), 124.0(\mathrm{CH}), 123.9(\mathrm{CH}), 123.7$ $(\mathrm{CH}), 123.3(\mathrm{CH}), 122.5(\mathrm{CH}), 120.7(\mathrm{CH}), 116.8(\mathrm{CH}), 111.1(\mathrm{CH}), 110.2(\mathrm{CH}), 91.4(\mathrm{CH}), 61.8\left(\mathrm{OCH}_{3}\right), 56.0$ $\left(\mathrm{OCH}_{3}\right), 55.9\left(\mathrm{OCH}_{3}\right), 55.5\left(\mathrm{OCH}_{3}\right)$. HRMS (ESI-TOF): $\mathrm{m} / \mathrm{z}[\mathrm{M}+\mathrm{H}]^{+}$calculated for $\mathrm{C}_{27} \mathrm{H}_{25} \mathrm{O}_{5} \mathrm{~S}, 461.1423$; found, 461.1417.

(E)-1-(3-(Benzo[b]thiophen-3-yl)-2,4,6-trimethoxyphenyl)-3-(3-fluorophenyl)prop-2-en-1-one (10). To a solution of 1-(3-(benzo[b]thiophen-3-yl)-2,4,6-trimethoxyphenyl)ethan-1-one (3) (100 $\mathrm{mg}, 0.29 \mathrm{mmol})$ in methanol $(3 \mathrm{~mL}$ ) was mixed in 3-fluorobenzaldehyde $(50 \mu \mathrm{L}, 0.47 \mathrm{mmol}$ ) and $\mathrm{KOH}$ ( $50 \%$ in water solution, 2 $\mathrm{mL}$ ). After stirring for $24 \mathrm{~h}$ at $\mathrm{rt}$, the solvent was removed under vacuum and the mixture was extracted with saturated $\mathrm{NH}_{4} \mathrm{Cl}$ solution and $\mathrm{CH}_{2} \mathrm{Cl}_{2}$, and dried over $\mathrm{Na}_{2} \mathrm{SO}_{4}$. The crude material was purified via column chromatography over silica gel using gradient elution with EtOAc/hexanes (20:80) to yield 10 as a light yellow solid $(130 \mathrm{mg}, 100 \%) . \mathrm{R}_{\mathrm{f}}($ EtOAc/Hexanes $2: 8)=0.3 . \mathrm{mp} 136-138^{\circ} \mathrm{C} . \mathrm{IR}\left(\mathrm{v}_{\max } \mathrm{cm}^{-1}\right): 2923,1641,1579,1456$, 1334, 1270, 1201, 1104. ${ }^{1} \mathrm{H}$ NMR $\left(600 \mathrm{MHz}, \mathrm{CDCl}_{3}\right) \delta 7.89$ (d, J $\left.7.4 \mathrm{~Hz}, 1 \mathrm{H}, \mathrm{CH}\right), 7.48(\mathrm{~d}, J 7.3 \mathrm{~Hz}, 1 \mathrm{H}, \mathrm{CH}), 7.43$ (t, J $7.8 \mathrm{~Hz}, 2 \mathrm{H}, \mathrm{CH}), 7.40-7.30(\mathrm{~m}, 4 \mathrm{H}, \mathrm{CH}), 7.29-7.23(\mathrm{~m}, 1 \mathrm{H}, \mathrm{CH}), 7.08(\mathrm{t}, J 7.7 \mathrm{~Hz}, 1 \mathrm{H}, \mathrm{CH}), 7.03(\mathrm{~d}, J 16.1$ $\mathrm{Hz}, 1 \mathrm{H}, \mathrm{CH}), 6.44(\mathrm{~s}, 1 \mathrm{H}, \mathrm{CH}), 3.90\left(\mathrm{~s}, 3 \mathrm{H}, \mathrm{OCH}_{3}\right), 3.77\left(\mathrm{~s}, 3 \mathrm{H}, \mathrm{OCH}_{3}\right), 3.22\left(\mathrm{~s}, 3 \mathrm{H}, \mathrm{OCH}_{3}\right) .{ }^{13} \mathrm{C} \mathrm{NMR}(150 \mathrm{MHz}$, $\mathrm{CDCl}_{3}$ ) $\delta 193.8(\mathrm{CO}), 163.8(\mathrm{CH}), 162.1(\mathrm{CH}), 160.4(\mathrm{CH}), 158.1(\mathrm{CH}), 158.1(\mathrm{CH}), 143.0(\mathrm{CH}), 139.4(\mathrm{CH}), 139.0$ $(\mathrm{CH}), 137.1(\mathrm{CH}), 137.1(\mathrm{CH}), 130.4(\mathrm{CH}), 130.3(\mathrm{CH}), 129.9(\mathrm{CH}), 128.4(\mathrm{CH}), 125.8(\mathrm{CH}), 124.4(\mathrm{CH}), 124.4(\mathrm{CH})$, 
$124.1(\mathrm{CH}), 123.9(\mathrm{CH}), 123.2(\mathrm{CH}), 122.6(\mathrm{CH}), 117.2(\mathrm{CH}), 117.1(\mathrm{CH}), 116.5(\mathrm{CH}), 114.7(\mathrm{CH}), 114.5(\mathrm{CH}), 110.4$ $(\mathrm{CH}), 91.4(\mathrm{CH}), 61.9\left(\mathrm{OCH}_{3}\right), 56.0\left(\mathrm{OCH}_{3}\right), 55.9\left(\mathrm{OCH}_{3}\right)$. HRMS (ESI-TOF): $m / z[\mathrm{M}+\mathrm{H}]^{+}$calculated for $\mathrm{C}_{26} \mathrm{H}_{22} \mathrm{FO}_{4} \mathrm{~S}$, 449.1223; found, 449.1188.

(E)-1-(3-(Benzo[b]thiophen-3-yl)-2,4,6-trimethoxyphenyl)-3-(4-fluorophenyl)prop-2-en-1-one (11). To a solution of 1-(3-(benzo[b]thiophen-3-yl)-2,4,6-trimethoxyphenyl)ethan-1-one (3) (100 $\mathrm{mg}, 0.29 \mathrm{mmol})$ in methanol $(3 \mathrm{~mL}$ ) was mixed in 4-fluorobenzaldehyde $(50 \mu \mathrm{L}, 0.47 \mathrm{mmol}$ ) and $\mathrm{KOH}$ ( $50 \%$ in water solution, 2 $\mathrm{mL}$ ). After stirring for $24 \mathrm{~h}$ at $\mathrm{rt}$, the solvent was removed under vacuum and the mixture was extracted with saturated $\mathrm{NH}_{4} \mathrm{Cl}$ solution and $\mathrm{CH}_{2} \mathrm{Cl}_{2}$, and dried over $\mathrm{Na}_{2} \mathrm{SO}_{4}$. The crude material was purified via column chromatography over silica gel using gradient elution with EtOAc/hexanes (20:80) to yield $\mathbf{1 1}$ as a yellow solid

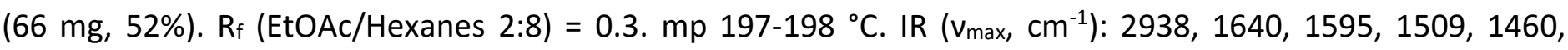
1336, 1232, 1165, 1102. ${ }^{1} \mathrm{H}$ NMR $\left(600 \mathrm{MHz}, \mathrm{CDCl}_{3}\right) \delta 7.89(\mathrm{~d}, J 7.1 \mathrm{~Hz}, 1 \mathrm{H}, \mathrm{CH}), 7.57-7.53(\mathrm{~m}, 2 \mathrm{H}, \mathrm{CH}), 7.51-$ $7.41(\mathrm{~m}, 3 \mathrm{H}, \mathrm{CH}), 7.39-7.30(\mathrm{~m}, 2 \mathrm{H}, \mathrm{CH}), 7.08(\mathrm{t}, \mathrm{J} 8.3 \mathrm{~Hz}, 2 \mathrm{H}, \mathrm{CH}), 6.97(\mathrm{~d}, J 16.0 \mathrm{~Hz}, 1 \mathrm{H}, \mathrm{CH}), 6.44(\mathrm{~s}, 1 \mathrm{H}, \mathrm{CH})$, $3.89\left(\mathrm{~s}, 3 \mathrm{H}, \mathrm{OCH}_{3}\right), 3.77\left(\mathrm{~s}, 3 \mathrm{H}, \mathrm{OCH}_{3}\right), 3.20\left(\mathrm{~s}, 3 \mathrm{H}, \mathrm{OCH}_{3}\right) ;{ }^{13} \mathrm{C} \mathrm{NMR}\left(150 \mathrm{MHz}, \mathrm{CDCl}_{3}\right) \delta 194.0(\mathrm{CO}), 164.8(\mathrm{CH})$, $163.1(\mathrm{CH}), 160.2(\mathrm{CH}), 158.1(\mathrm{CH}), 158.0(\mathrm{CH}), 143.4(\mathrm{CH}), 139.4(\mathrm{CH}), 139.0(\mathrm{CH}), 131.0(\mathrm{CH}), 131.0(\mathrm{CH}), 130.4$ $(\mathrm{CH}), 130.3(\mathrm{CH}), 128.5(\mathrm{CH}), 128.5(\mathrm{CH}), 128.5(\mathrm{CH}), 125.8(\mathrm{CH}), 124.1(\mathrm{CH}), 123.9(\mathrm{CH}), 123.2(\mathrm{CH}), 122.6(\mathrm{CH})$, $116.6(\mathrm{CH}), 116.1(\mathrm{CH}), 115.9(\mathrm{CH}), 110.4(\mathrm{CH}), 91.4(\mathrm{CH}), 61.7\left(\mathrm{OCH}_{3}\right), 56.0\left(\mathrm{OCH}_{3}\right), 55.9\left(\mathrm{OCH}_{3}\right)$. HRMS (ESITOF): $\mathrm{m} / \mathrm{z}[\mathrm{M}+\mathrm{H}]^{+}$calculated for $\mathrm{C}_{26} \mathrm{H}_{22} \mathrm{FO}_{4} \mathrm{~S}, 449.1223$; found, 449.1191.

(E)-1-(3-(Benzo[b]thiophen-3-yl)-2,4,6-trimethoxyphenyl)-3-(4-methoxyphenyl)prop-2-en-1-one (12). To a solution of 1-(3-(benzo[b]thiophen-3-yl)-2,4,6-trimethoxyphenyl)ethan-1-one (3) (100 mg, $0.29 \mathrm{mmol})$ in methanol $(3 \mathrm{~mL})$ was mixed in 4-fluorobenzaldehyde $(50 \mu \mathrm{L}, 0.47 \mathrm{mmol})$ and $\mathrm{KOH}(50 \%$ in water solution, 2 $\mathrm{mL}$ ). After stirring for $24 \mathrm{~h}$ at $\mathrm{rt}$, the solvent was removed under vacuum and the mixture was extracted with saturated $\mathrm{NH}_{4} \mathrm{Cl}$ solution and $\mathrm{CH}_{2} \mathrm{Cl}_{2}$, and dried over $\mathrm{Na}_{2} \mathrm{SO}_{4}$. The crude material was purified via column chromatography over silica gel using gradient elution with EtOAc/hexanes (20:80) to yield 12 as a white solid $(40 \mathrm{mg}, 30 \%) . \mathrm{R}_{\mathrm{f}}\left(\right.$ EtOAc/Hexanes 2:8) $=0.2 \mathrm{mp} \mathrm{209-210}{ }^{\circ} \mathrm{C} . \mathrm{IR}\left(\mathrm{v}_{\max }, \mathrm{cm}^{-1}\right): 2925,1637,1597,1512,1464$, 1256, 1172, 1098. ${ }^{1} \mathrm{H}$ NMR $\left(600 \mathrm{MHz}, \mathrm{CDCl}_{3}\right) \delta 7.89(\mathrm{~d}, \mathrm{~J} 7.6 \mathrm{~Hz}, 1 \mathrm{H}, \mathrm{CH}), 7.56-7.46(\mathrm{~m}, 3 \mathrm{H}, \mathrm{CH}), 7.46-7.38$ $(\mathrm{m}, 2 \mathrm{H}, \mathrm{CH}), 7.38-7.29(\mathrm{~m}, 2 \mathrm{H}, \mathrm{CH}), 6.97-6.87(\mathrm{~m}, 3 \mathrm{H}, \mathrm{CH}), 6.44(\mathrm{~s}, 1 \mathrm{H}, \mathrm{CH}), 3.88\left(\mathrm{~s}, 3 \mathrm{H}, \mathrm{OCH}_{3}\right), 3.84(\mathrm{~s}, 3 \mathrm{H}$, $\left.\mathrm{OCH}_{3}\right), 3.77\left(\mathrm{~s}, 3 \mathrm{H}, \mathrm{OCH}_{3}\right), 3.20\left(\mathrm{~s}, 3 \mathrm{H}, \mathrm{OCH}_{3}\right) .{ }^{13} \mathrm{C} \mathrm{NMR}\left(150 \mathrm{MHz}, \mathrm{CDCl}_{3}\right) \delta 194.4(\mathrm{CO}), 161.6(\mathrm{CH}), 160.0(\mathrm{CH})$, $158.0(\mathrm{CH}), 157.8(\mathrm{CH}), 145.0(\mathrm{CH}), 139.4(\mathrm{CH}), 139.0(\mathrm{CH}), 130.2(\mathrm{CH}), 128.6(\mathrm{CH}), 127.4(\mathrm{CH}), 126.7(\mathrm{CH}), 125.8$ $(\mathrm{CH}), 124.0(\mathrm{CH}), 123.9(\mathrm{CH}), 123.3(\mathrm{CH}), 122.5(\mathrm{CH}), 116.9(\mathrm{CH}), 114.3(\mathrm{CH}), 110.3(\mathrm{CH}), 91.4(\mathrm{CH}), 61.8\left(\mathrm{OCH}_{3}\right)$, $56.0\left(\mathrm{OCH}_{3}\right), 55.9\left(\mathrm{OCH}_{3}\right), 55.4\left(\mathrm{OCH}_{3}\right)$. HRMS (ESI-TOF): $\mathrm{m} / \mathrm{z}[\mathrm{M}+\mathrm{H}]^{+}$calculated for $\mathrm{C}_{27} \mathrm{H}_{25} \mathrm{O}_{5} \mathrm{~S}, 461.1423$; found, 449.1414.

(E)-1-(3-(Benzo[b]thiophen-3-yl)-2,4,6-trimethoxyphenyl)-3-(2,5-difluoro-4-methoxyphenyl)prop-2-en-1-one (13). To a solution of 1-(3-(benzo[b]thiophen-3-yl)-2,4,6-trimethoxyphenyl)ethan-1-one (3) (100 mg, 0.29 $\mathrm{mmol}$ ) in methanol $(3 \mathrm{~mL}$ ) was mixed in 2,4,5-trifluorobenzaldehyde (53 $\mu \mathrm{L}, 0.47 \mathrm{mmol}$ ) and $\mathrm{KOH}(50 \%$ in water solution, $2 \mathrm{~mL}$ ). After stirring for $24 \mathrm{~h}$ at $\mathrm{rt}$, the solvent was removed under vacuum and the mixture was extracted with saturated $\mathrm{NH}_{4} \mathrm{Cl}$ solution and $\mathrm{CH}_{2} \mathrm{Cl}_{2}$, and dried over $\mathrm{Na}_{2} \mathrm{SO}_{4}$. The crude material was purified via column chromatography over silica gel using gradient elution with EtOAc/hexanes (20:80) to yield 13 as a yellow solid (95 mg, 66\%). $\mathrm{R}_{\mathrm{f}}$ (EtOAc/Hexanes $\left.2: 8\right)=0.26 . \mathrm{mp} 169-171{ }^{\circ} \mathrm{C}$. IR $\left(\mathrm{v}_{\mathrm{max}}, \mathrm{cm}^{-1}\right): 2923,1663,1593$, 1507, 1442, 1330, 1297, 1194, 1103. ${ }^{1} \mathrm{H}$ NMR $\left(600 \mathrm{MHz}, \mathrm{CDCl}_{3}\right) \delta 7.88$ (d, J $\left.7.2 \mathrm{~Hz}, 1 \mathrm{H}, \mathrm{CH}\right), 7.54(\mathrm{~d}, J 16.1 \mathrm{~Hz}$, $1 \mathrm{H}, \mathrm{CH}), 7.48(\mathrm{~d}, J 7.8 \mathrm{~Hz}, 1 \mathrm{H}, \mathrm{CH}), 7.42(\mathrm{~s}, 1 \mathrm{H}, \mathrm{CH}), 7.38-7.29(\mathrm{~m}, 3 \mathrm{H}, \mathrm{CH}), 6.94(\mathrm{~d}, J 16.2 \mathrm{~Hz}, 1 \mathrm{H}, \mathrm{CH}), 6.70(\mathrm{dd}$, J 11.2, $7.0 \mathrm{~Hz}, 1 \mathrm{H}, \mathrm{CH}), 6.43(\mathrm{~s}, 1 \mathrm{H}, \mathrm{CH}), 3.90\left(\mathrm{~s}, 3 \mathrm{H}, \mathrm{OCH}_{3}\right), 3.89\left(\mathrm{~s}, 3 \mathrm{H}, \mathrm{OCH}_{3}\right), 3.77\left(\mathrm{~s}, 3 \mathrm{H}, \mathrm{OCH}_{3}\right), 3.20(\mathrm{~s}, 3 \mathrm{H}$, $\left.\mathrm{OCH}_{3}\right) .{ }^{13} \mathrm{C} \mathrm{NMR}\left(150 \mathrm{MHz}, \mathrm{CDCl}_{3}\right) \delta 193.8(\mathrm{CO}), 160.3(\mathrm{CH}), 158.1(\mathrm{CH}), 158.0(\mathrm{CH}), 139.4(\mathrm{CH}), 139.0(\mathrm{CH})$, $135.7(\mathrm{CH}), 129.3(\mathrm{CH}), 129.2(\mathrm{CH}), 128.5(\mathrm{CH}), 125.8(\mathrm{CH}), 124.0(\mathrm{CH}), 123.9(\mathrm{CH}), 123.3(\mathrm{CH}), 122.5(\mathrm{CH}), 116.5$ $(\mathrm{CH}), 114.3(\mathrm{CH}), 114.3(\mathrm{CH}), 114.2(\mathrm{CH}), 114.1(\mathrm{CH}), 110.4(\mathrm{CH}), 101.5(\mathrm{CH}), 101.3(\mathrm{CH}), 91.4(\mathrm{CH}), 61.8\left(\mathrm{OCH}_{3}\right)$, 
$56.5\left(\mathrm{OCH}_{3}\right), 56.0\left(\mathrm{OCH}_{3}\right), 55.9\left(\mathrm{OCH}_{3}\right)$. HRMS (ESI-TOF): $\mathrm{m} / \mathrm{z}[\mathrm{M}+\mathrm{H}]^{+}$calculated for $\mathrm{C}_{27} \mathrm{H}_{23} \mathrm{~F}_{2} \mathrm{O}_{5} \mathrm{~S}, 497.1234$; found, 497.1180 .

(E)-1-(3-(Benzo[b]thiophen-3-yl)-2,4,6-trimethoxyphenyl)-3-(5-fluoro-2,4-dimethoxyphenyl)prop-2-en-1-one (14). To a solution of 1-(3-(benzo[b]thiophen-3-yl)-2,4,6-trimethoxyphenyl)ethan-1-one (3) (100 mg, 0.29 $\mathrm{mmol}$ ) in methanol $(3 \mathrm{~mL}$ ) was mixed in 2,4,5-trifluorobenzaldehyde (53 $\mu \mathrm{L}, 0.47 \mathrm{mmol}$ ) and $\mathrm{KOH}(50 \%$ in water solution, $2 \mathrm{~mL}$ ). After stirring for $24 \mathrm{~h}$ at $\mathrm{rt}$, the solvent was removed under vacuum and the mixture was extracted with saturated $\mathrm{NH}_{4} \mathrm{Cl}$ solution and $\mathrm{CH}_{2} \mathrm{Cl}_{2}$, and dried over $\mathrm{Na}_{2} \mathrm{SO}_{4}$. The crude material was purified via column chromatography over silica gel using gradient elution with EtOAc/hexanes (20:80) to yield 14 as a

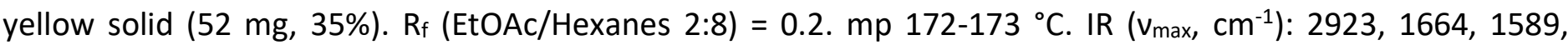
1506, 1440, 1299, 1204, 1107. ${ }^{1} \mathrm{H}$ NMR $\left(600 \mathrm{MHz}, \mathrm{CDCl}_{3}\right) \delta 7.89(\mathrm{~d}, J 7.2 \mathrm{~Hz}, 1 \mathrm{H}, \mathrm{CH}), 7.73(\mathrm{~d}, J 16.2 \mathrm{~Hz}, 1 \mathrm{H}, \mathrm{CH})$, 7.50 (d, J $7.7 \mathrm{~Hz}, 1 \mathrm{H}, \mathrm{CH}), 7.42(\mathrm{~s}, 1 \mathrm{H}, \mathrm{CH}), 7.36-7.29(\mathrm{~m}, 3 \mathrm{H}, \mathrm{CH}), 6.94(\mathrm{~d}, J 16.1 \mathrm{~Hz}, 1 \mathrm{H}, \mathrm{CH}), 6.49(\mathrm{~d}, J 7.0 \mathrm{~Hz}$, $1 \mathrm{H}, \mathrm{CH}), 6.43(\mathrm{~s}, 1 \mathrm{H}, \mathrm{CH}), 3.93\left(\mathrm{~s}, 3 \mathrm{H}, \mathrm{OCH}_{3}\right), 3.88\left(\mathrm{~s}, 3 \mathrm{H}, \mathrm{OCH}_{3}\right), 3.85\left(\mathrm{~s}, 3 \mathrm{H}, \mathrm{OCH}_{3}\right), 3.77\left(\mathrm{~s}, 3 \mathrm{H}, \mathrm{OCH}_{3}\right), 3.20(\mathrm{~s}$, $\left.3 \mathrm{H}, \mathrm{OCH}_{3}\right) .{ }^{13} \mathrm{C} \mathrm{NMR}\left(150 \mathrm{MHz}, \mathrm{CDCl}_{3}\right) \delta 194.5(\mathrm{CO}), 160.0(\mathrm{CH}), 158.0(\mathrm{CH}), 157.8(\mathrm{CH}), 155.6(\mathrm{CH}), 150.3(\mathrm{CH})$, $150.2(\mathrm{CH}), 147.5(\mathrm{CH}), 146.0(\mathrm{CH}), 139.4(\mathrm{CH}), 139.1(\mathrm{CH}), 130.9(\mathrm{CH}), 128.6(\mathrm{CH}), 127.7(\mathrm{CH}), 125.7(\mathrm{CH}), 124.0$ $(\mathrm{CH}), 123.9(\mathrm{CH}), 123.3(\mathrm{CH}), 122.5(\mathrm{CH}), 117.0(\mathrm{CH}), 115.8(\mathrm{CH}), 115.8(\mathrm{CH}), 115.0(\mathrm{CH}), 114.9(\mathrm{CH}), 110.2(\mathrm{CH})$, $97.6(\mathrm{CH}), 91.4(\mathrm{CH}), 61.8\left(\mathrm{OCH}_{3}\right), 56.4\left(\mathrm{OCH}_{3}\right), 56.3\left(\mathrm{OCH}_{3}\right), 56.0\left(\mathrm{OCH}_{3}\right), 55.9\left(\mathrm{OCH}_{3}\right)$.

\section{Acknowledgements}

This work was supported by Kilis 7 Aralik University, Scientific Research Projects Coordinatorship (BAP 1813012)

\section{Supplementary Material}

Copies of ${ }^{1} \mathrm{H}$ and ${ }^{13} \mathrm{C}$ NMR spectra are provided in the Supplementary Material file associated with this paper.

\section{References}

1. Moon, Y. J.; Wang, X.; \& Morris, M. E. Toxicology in vitro 2006, 20(2), 187-210. https://doi.org/10.1016/i.tiv.2005.06.048

2. Burmaoglu, S.; Akin Kazancioglu, E.; Kaya R.; Kazancioglu, M.; Karaman, M.; Algul, O.; Gulcin, I. Journal of Molecular Structure. 2020, 1208, 127868.

10.1016/j.molstruc.2020.127868

3. Demirayak, S.; Yurttas, L.; Gundogdu-Karaburun, N.; Cagri Karaburun, A.; Kayagil, I. Saudi Pharm J. 2017, 25, 1063-1072.

https://doi.org/10.1016/j.jsps.2017.04.040

4. Gates, M.A.; Vitonis, A.F.; Tworoger, S.S.; Rosner, B.; Titus-Ernstoff, L.; Hankinson, S.E.; Cramer, D.W. Int J Cancer 2009, 24, 1918-1925.

https://doi.org/10.1002/ijc.24151

5. López-Lázaro, M. Anti-cancer agents, 2002, 2, 691-714.

https://doi.org/10.2174/1568011023353714 
6. Zuo, Y.; Yu, Y.; Wang, S.; Shao, W.; Zhou, B.; Lin, L.; Luo, Z.; Huang, R.; Du, J.; Bu, X. Eur J Med Chem. 2012, 50, 393-404.

https://doi.org/10.1016/i.ejmech.2012.02.023

7. Koizumi, N.; Takegawa, S.; Iwashita ,S.; Kawachi, T.; Matsui, T.; Mieda, M.; Takahashi, H.; Saito, T.; Shibata, K. U.S. Patent, 1995, US5472962A.

8. McDonnell, D. P. Trends Endocrinol Metab. 1999,10, 301-311. https://doi.org/10.1016/s1043-2760(99)00177-0

9. Toy, W.; Shen, Y.; Won, H.; Green, B.; Sakr, R. A.; Will, M.; Li, Z.; Gala, K.; Fanning, S.; King, T. A.; Hudis, C.; Chen, D.; Taran, T.; Hortobagyi, G.; Greene, G.; Berger, M.; Baselga, J.; Chandarlapaty, S. Nat Genet. 2013, $45,1439-1445$.

https://doi.org/10.1038/ng.2822

10. Robinson, D. R.; Wu, Y. M.; Vats, P.; Su, F.; Lonigro, R. J.; Cao, X.; Kalyana-Sundaram, S.; Wang, R.; Ning, Y.; Hodges, L.; Gursky, A.; Siddiqui, J.; Tomlins, S. A.; Roychowdhury, S.; Pienta, K. J.; Kim, S. Y.; Roberts, J. S.; Rae, J. M.; Van Poznak, C. H.; Hayes, D. F.; Chugh, R.; Kunju, L. P.; Talpaz, M.; Schott, A. F.; Chinnaiyan, A. M. Nat. Genet. 2013, 45, 1446-1451.

https://doi.org/10.1038/ng.2823

11. Xiong, R.; Zhao, J.; Gutgesell, L. M.; Wang, Y.; Lee, S.; Karumudi, B.; Zhao, H.; Lu, Y.; Tonetti, D. A.; Thatcher, G. R. J Med Chem. 2017, 60, 1325-1342.

https://doi.org/10.1021/acs.jmedchem.6b01355

12. Yoneya, T.; Taniguchi, K.; Nakamura, R.; Tsunenari, T.; Ohizumi, I.; Kanbe, Y.; Morikawa, K.; Kaiho, S.; Yamada-Okabe, H. Anticancer Res. 2010, 30, 873-878.

13. Vargas, E.; Echeverri, F.; Vélez, I. D.; Robledo, S. M.; Quiñones, W. Molecules. 2017, 22, 2041. https://doi.org/10.3390/molecules22122041

14. Marć, M. A.; Kincses, A.; Rácz, B.; Nasim, M. J.; Sarfraz, M.; Lázaro-Milla, C.; Domínguez-Álvarez, E.; Jacob, C.; Spengler, G.; Almendros, P. Pharmaceuticals (Basel). 2020, 13, 453. https://doi.org/10.3390/ph13120453

15. Gomes, M. N.; Muratov, E. N.; Pereira, M.; Peixoto, J. C.; Rosseto, L. P.; Cravo, P.; Andrade, C. H.; Neves, B. J. Molecules. 2017, 22, 1210.

https://doi.org/10.3390/molecules22081210

16. Asiri, A. M.; Khan, S. A. Molecules. 2011, 16, 523-531.

https://doi.org/10.3390/molecules16010523

17. Mahapatra, D. K.; Bharti, S. K.; Asati, V. Eur J Med Chem. 2015, 98, 69-114. https://doi.org/10.1016/i.ejmech.2015.05.004

18. Han, Y.; Riwanto, M.; Go, M. L.; Ee, P. L. Eur J Pharm Sci. 2008, 35, 30-41. https://doi.org/10.1016/i.ejps.2008.06.001

19. Sharma, A.; Chakravarti, B.; Gupt, M. P.; Siddiqui, J. A.; Konwar, R.; Tripathi, R. P. Bioorg Med Chem. 2010, $18,4711-4720$.

https://doi.org/10.1016/i.bmc.2010.05.015

20. Zhuang, C.; Zhang, W.; Sheng, C.; Zhang, W.; Xing, C.; Miao, Z. Chem Rev. 2017, 117, 7762-7810. https://doi.org/10.1021/acs.chemrev.7b00020

21. Juvale, K.; Pape, V. F.; Wiese, M. Bioorg. Med. Chem., 2012, 20, 346-355. https://doi.org/10.1016/j.bmc.2011.10.074

22. Solomon, V.R.; Lee, H. Biomed Pharmacother. 2012, 66, 213-20. https://doi.org/10.1016/j.biopha.2011.11.013 
23. Burmaoglu, S.; Yilmaz, A. O.; Polat, M. F.; Kaya, R.; Gulcin, i.; Algul, O. Arch Physiol Biochem. 2021, 127, 153-161.

https://doi.org/10.1080/13813455.2019.1623265

24. Olsen, J. A.; Banner, D. W.; Seiler, P.; Wagner, B.; Tschopp, T.; Obst-Sander, U.; Kansy, M.; Müller, K.; Diederich, F. Chembiochem. 2004, 5, 666-675.

https://doi.org/10.1002/cbic.200300907

25. Burmaoglu, S.; Yilmaz, A. O.; Polat, M. F.; Kaya, R.; Gulcin, I..; Algul, O. Bioorg Chem. 2019, 85, $191-197$. https://doi.org/10.1016/j.bioorg.2018.12.035

26. Biffinger, J. C.; Kim, H. W.; DiMagno, S. G. Chembiochem. 2004, 5, 622-627. https://doi.org/10.1002/cbic.200300910

27. Clayden, J.; Greeves, N.; Warren, S.; Wothers P. in Organic Chemistry, Oxford University Press, 2008, pp. 593. 